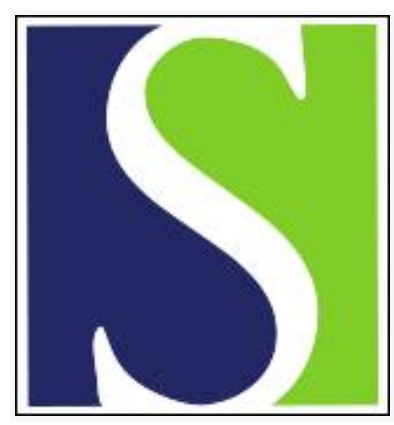

Scand J Work Environ Health 2012;38(1):38-46

https://doi.org/10.5271/sjweh.3178

Published online: 22 Jun 2011, Issue date: Jan 2012

Longitudinal relationships between workplace bullying and psychological distress

by Nielsen MB, Hetland J, Matthiesen SB, Einarsen S

Affiliation: Department of Psychosocial Science, University of Bergen, Christiesgate 12, NO-5015 Bergen, Norway. morten.nielsen@uib.no

Refers to the following texts of the Journal: 2004;30 suppl 2:36-46 2011;37(3):204-212 2011;37(4):276-287 2011;37(4):259-261

The following articles refer to this text: 2012;38(3):218-227;

2016;42(3):246-250; 2018;44(3):283-290

Key terms: aggression; anxiety; depression; harassment; mental stress; mobbing; occupational stress; psycholological distress; workplace bullying

This article in PubMed: www.ncbi.nlm.nih.gov/pubmed/22638759

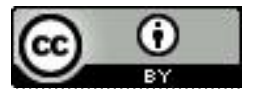




\title{
Longitudinal relationships between workplace bullying and psychological distress
}

\author{
by Morten Birkeland Nielsen, PhD, ${ }^{1}$ Jorn Hetland, PhD, ${ }^{1}$ Stig Berge Matthiesen, PhD, ${ }^{1}$ Ståle Einarsen, PhD ${ }^{1}$
}

\begin{abstract}
Nielsen MB, Hetland J, Matthiesen SB, Einarsen S. Longitudinal relationships between workplace bullying and psychological distress. Scand J Work Environ Health. 2012;38(1):38-46. doi:10.5271/sjweh.3178

Objectives The aims of this study were to examine reciprocal longitudinal associations between exposure to workplace bullying and symptoms of psychological distress and to investigate how self-labeled victimization from bullying explains the effects of bullying on health.
\end{abstract}

\begin{abstract}
Methods Logistic regression analysis was employed to examine the longitudinal relationships between workplace bullying and psychological distress in a representative cohort sample of 1775 Norwegian employees. The time-lag between baseline and follow-up was two years. Exposure to bullying behavior was measured with the revised version of the Negative Acts Questionnaire. Perceived victimization from bullying was measured by a single self-labeling question. Psychological distress was measured with the 25-item Hopkins Symptom Checklist. All variables were measured at both baseline and follow-up.
\end{abstract}

Results After adjustment for psychological distress at baseline, exposure to bullying behavior [odds ratio (OR) $1.68,95 \%$ confidence interval $(95 \% \mathrm{CI}) 1.07-2.62)$ was found to predict subsequent psychological distress. This effect of bullying behaviors disappeared when victimization from bullying (OR 2.47, 95\% CI 1.17-5.22) was entered into the regression. Both psychological distress (OR 2.49, 95\% CI 1.64-3.80) and victimization (OR $2.61,95 \% \mathrm{CI} 1.42-4.81$ ) at baseline were associated with increased risks of being a target of bullying behaviors at follow-up. Psychological distress (OR 2.51, 95\% CI 1.39-4.52) and bullying behaviors (OR 2.95, 95\% CI 1.39-4.52) at follow-up were associated with victimization.

Conclusion The mutual relationship between bullying and psychological distress indicates a vicious circle where bullying and distress reinforce their own negative effects. This highlights the importance of early interventions to stop workplace bullying and provide treatment options to employees with psychological distress.

Key terms aggression; anxiety; depression; harassment; mental stress; mobbing; occupational stress.

Workplace bullying is defined as a situation where one or several individuals persistently, and over a period of time, perceive themselves to be on the receiving end of negative actions from one or several persons, and where the target of the bullying finds it difficult to defend him- or herself against these actions (1). There is no definitive list of bullying behaviors, although in most cases it involves exposure to verbal hostility, being made the laughing stock of the department, or acts of social exclusion (2). In many cases, it is the summarized pattern of behaviors that constitute the menace, rather than the particular acts. Taken individually, such incidents may only be seen as mildly offensive, or at least tolerable, but accumulated, they can be experienced as destabilizing and highly distressing to the person on the receiving end (1). Victimization from bullying occurs when the target perceives the exposure to these behaviors as a threat to his or her fundamental psychological and physiological needs such as the sense of belonging, the feeling of being a worthy individual, and the ability to predict and cognitively control one's environment and avoid pain (3).

A number of studies have established an evident relationship between workplace bullying and psychological and physical health problems (eg, 4, 5). For instance, cross sectional evidence has shown that exposure to bullying is associated with mental and psychosomatic complaints (6-8), such as musculoskeletal problems, and in particular depression and anxiety $(7,9,10)$. However, as only a few studies have investigated associations

1 Department of Psychosocial Science, University of Bergen, Norway.

Correspondence to: Morten Birkeland Nielsen, Department of Psychosocial Science, University of Bergen, Christiesgate 12, NO-5015 Bergen, Norway. [E-mail: morten.nielsen@uib.no] 
between bullying and health over time (11-15), empirical evidence about the long-term relationships between bullying and health is limited. Yet, from a theoretical standpoint, both a stressor-strain and a strain-stressor relationship can be expected. With regard to the former, a common feature of most occupational stress models is that stressors in the work environment generate negative physical, psychological, or behavioral changes in the individual (16). Reviewing various models of stress, Beehr (17) concludes that there is ample evidence to suggest that stressors in the work environment may lead to dysfunctional intermediate psychological or physiological processes that subsequently result in adverse health effects among employees. For example, the core assumption of the cognitive activation theory of stress is that repeated or chronic cognitive activation in the form of worry or rumination, produced by stressors, may prolong physiological activation, which subsequently leads to impairment in health (18).

However, a strain-stressor relationship between bullying and health has also been put forward (ie, an explanation where personal characteristics such as impaired health and specific personality traits are assumed to constitute a vulnerability factor that may increase the risk of being bullied) (4). Hence, it may be that an individual's specific characteristics may predispose them to being bullied at the workplace (19). For instance, employees with impaired mental health may elicit aggressive behaviors in others by going against expectations, irritating colleagues, and violating social norms describing social interactions (20). Alternatively, a strain-stressor relationship may also be explained by the so-called "gloomy perception mechanism" (21). According to this mechanism, unhealthy employees (eg, depressive workers) report less favorable work characteristics because they evaluate their work environment more negatively than their colleagues. That is, because of their mental health problems, these employees have a gloomier perception of reality. Hence, it could be that employees with mental health problems perceive their work situation in a more hostile way and therefore report higher levels of workplace bullying.

Both the stressor-strain and strain-stressor models have gained support in the existing longitudinal research on workplace bullying $(11,14)$. For instance, a longitudinal study investigating workplace bullying and the risk of cardiovascular disease and depression over a two year period among 5432 Finnish hospital employees showed bullying to be an etiological factor for mental health problems; depression at baseline also predicted subsequent exposure to bullying, thus indicating a vicious circle (12). This suggests that poor health may both be a result of bullying as well as a factor increasing an individual's susceptibility to being bullied.

As for mechanisms that may explain the relationship between bullying and mental health, it has been proposed that the subjective perception of being victimized by exposure to bullying behaviors has important implications for the health consequences of targets (3). For instance, it is claimed that self-labeling as a victim of bullying produces an emotional reaction in the victim that amplifies the experienced health consequences compared to the effects of exposure to bullying behaviors alone (8). Yet, in line with the strain-stressor relationship between bullying and mental health presented above, persons with high levels of psychological distress may also have a lower threshold with regard to subsequent self-labeling.

In sum, the small body of existing theoretical and empirical evidence on the long-term relationships between workplace bullying and mental health indicates a mutual relationship between the variables. In addition, research suggests that victimization from bullying influences health outcomes among that those who perceive themselves as victims, causing them to experience more health problems.

To add to the very limited knowledge about how workplace bullying and mental health problems are related over time, the aim of this study is to investigate the longitudinal associations between psychological distress and workplace bullying as measured by both exposure to bullying behaviors and self-labeled victimization from bullying. Based on the theoretical models presented above, three hypotheses will be tested: (i) high level of workplace bullying at baseline is related to an increased risk of psychological distress at follow-up; (ii) high level of psychological distress at baseline is related to an increased risk of workplace bullying at follow-up; (iii) self-labeled victimization from bullying is more strongly related to psychological distress over time than exposure to bullying behavior.

\section{Method}

\section{Design and procedure}

This study is based on longitudinal data from a nationwide sample of the Norwegian working force. Data were collected at two different time-points, with a time lag of approximately two years. At baseline in 2005, Statistics Norway drew a random sample of 4500 employees from the Norwegian Central Employee Register (NCER). The sampling criteria comprised adults between 18-67 years of age, registered in the NCER as employed during the last six months before the survey in an enterprise with a staff of $\geq 5$ and with a mean working time of $>15$ hours per week.

Questionnaires were distributed through the 
Norwegian postal service to the respondents' home addresses. Altogether 2539 questionnaires were returned (57\% response rate). This response rate is slightly higher than typically found in this kind of workplace survey study (22). Using the same procedure, the second wave of data was collected in 2007 at follow-up. All respondents from the baseline survey were asked to participate. The response rate for the follow-up survey was $70 \%$, yielding an overall cohort participation rate of $40 \%$. With the exception of a somewhat skewed gender distribution, the cohort sample can be considered as representative of the Norwegian working population with regard to demographic characteristics $(23,24)$. The Regional Committee for Medical Research Ethics in Western Norway approved the study.

\section{Participants}

Of the 1775 respondents who took part in both waves of data collection, women were slightly overrepresented $(55 \%)$. At baseline, the mean age of the sample was 46.5 years. Altogether, $85 \%$ of the respondents were employed in a full- $(68 \%)$ or part-time $(17 \%)$ position, while $15 \%$ were on temporary sick leave, paid leave, or vocational rehabilitation. A majority $(75 \%)$ had a regular daytime working arrangement. Mean working hours per week was 37.5. Attrition analyses of demographic data at baseline, including dropouts, revealed that the cohort respondents [mean 45.22, standard deviation (SD) $11.38 ; \mathrm{N}=1771]$ were somewhat older than dropout respondents (mean 40.49, SD 11.29; $\mathrm{N}=768)(\mathrm{t}=9.67$; $\mathrm{df}=2537 ; \mathrm{P}<0.000)$. In addition, systematic gender differences $\left(\chi^{2}=25.06 ; \mathrm{df}=1 ; \mathrm{P}<0.000\right)$ were revealed between cohort (55\% women) and dropouts $(45 \%)$ at baseline. As for the study variables, no differences between cohort and dropouts were found with regard to psychological distress or victimization. However, compared to the cohort sample (11\%), significantly more of the dropouts $(15 \%)$ reported exposure to bullying behavior at baseline $\left(\chi^{2}=6.56\right.$; $\left.\mathrm{df}=1 ; \mathrm{P}<0.013\right)$.

\section{Instruments}

Exposure to bullying behaviors in the workplace was measured with the 22-item Negative Acts Questionnaire - Revised (NAQ-R) inventory (25). NAQ-R describes different behaviors that may be perceived as bullying if occurring on a regular basis. All items are formulated in behavioral terms. The NAQ-R contains items referring to both direct (eg, openly attacking the victim) and indirect (eg, social isolation, slander) behaviors. It also contains items referring to personal as well as work-related forms of bullying. Example items include: "having your opinions and views ignored" and "spreading of gossip and rumors about you". For each item, the respondents were asked how often they had been exposed to the behavior at their present worksite during the last six months. Response categories range from 1-5 ("never", "now and then", "monthly", "weekly" and "daily"). In accordance with recent advances on the use of cut-off criteria with regard to estimating targets of bullying (26), respondents with a summarized score of $\geq 33$ on the NAQ-R were classified as targets of workplace bullying. Compared to earlier attempts to define cut-off scores such as the Leymann criterion (27), this cut-off score of 33 is founded on statistical procedures that takes both the sensitivity and specificity of the items into account. Direct comparisons of the different cut-off criteria show that the 33 score criterion has the highest reliability and validity (26).

In line with previous studies (eg, 28), perceived victimization from bullying was measured by asking the respondents to indicate whether they considered themselves to have been victimized by bullying at work during the last six months according to the following definition: "Bullying takes place when one or more persons systematically and over time feel that they have been subjected to negative treatment on the part of one or more persons, in a situation in which the person(s) exposed to the treatment have difficulty in defending themselves against them. It is not bullying when two equally strong opponents are in conflict with each other" (29, p191). The response categories were: "no", "yes, rarely", "yes, now and then", "yes, once a week", and "yes, several times a week". Respondents answering any of the "yes" responses to this question were categorized as victims of bullying.

Mental health was assessed with the Hopkins Symptoms Checklist-25 (HSCL-25), a widely used screening measure that covers the most common psychiatric symptoms in the area of anxiety and depression (30). Example items are "headache", "difficulties falling asleep", and "a lack of interest for things". The HSCL-25 is scored on a severity scale from 1 ("not at all") to 4 ("extremely") using the "last week" as a frame of reference when answering. Mental caseness, that is the need for treatment, is calculated by having an average score on the HSCL-25 items of $\geq 1.75$ (cf. 31). The comparison of scores on the HSCL-25 to physician ratings of emotional distress has yielded a concordance rate of $86.7 \%$ (32). The HSCL-25 has satisfactory validity and reliability as a measure of psychological distress $(31,33)$.

\section{Statistical analysis}

Statistical analyses were conducted using IBM SPSS statistics 18.0 (SPSS Inc, Chicago, IL, USA). Frequency analyses were employed to investigate prevalence and incidence of workplace bullying and psychological distress. A series of logistic regression analyses were 
conducted in order to examine longitudinal relationships between bullying and psychological distress. The level of significance was set to 0.05 .

\section{Results}

Prevalence, incidence, and stability of workplace bullying and psychological distress

The prevalence estimates of workplace bullying and psychological distress at baseline and follow-up are presented in table 1 . The prevalence of exposure to bullying behavior is higher than estimates based on self-labeled victimization from bullying. With regard to the incidence of bullying, $7 \%$ were targets of bullying behaviors at baseline, but not at follow-up. At follow-up, $5 \%$ were new targets of bullying behaviors, whereas $5 \%$ were targets at both time points. When using self-labeled victimization to estimate the incidence of workplace bullying, $3 \%$ were new cases at follow-up, $2 \%$ were victims at baseline but not at follow-up, and 2\% reported being victims at both baseline and follow-up. As for the incidence of psychological distress, $6 \%$ had symptoms of psychological distress at baseline but not at follow-up, $6 \%$ were new cases at follow-up, and $7 \%$ had symptoms of distress at both time-points.

\section{Longitudinal associations between bullying and} psychological distress

A two-step logistic regression analysis was used to investigate the effects of bullying behavior and victimization at baseline on psychological distress at followup. Psychological distress and exposure to bullying behaviors at baseline were entered as predictors in the first step, while self-labeled victimization at baseline was included in the second step of the analysis. After adjusting for psychological distress at baseline, exposure

Table 1. Prevalence of workplace bullying and psychological distress at baseline and follow-up.

\begin{tabular}{|c|c|c|c|c|}
\hline & \multicolumn{4}{|c|}{ Survey time } \\
\hline & \multicolumn{2}{|c|}{ Baseline } & \multicolumn{2}{|c|}{ Follow-up } \\
\hline & $\mathrm{N}$ & $\%$ & $\mathrm{~N}$ & $\%$ \\
\hline \multicolumn{5}{|c|}{ Psychological distress } \\
\hline No & 1451 & 87 & 1373 & 87.2 \\
\hline Yes & 215 & 13 & 201 & 12.8 \\
\hline \multicolumn{5}{|c|}{ Targets of bullying behaviors } \\
\hline Non-targets & 1570 & 88.5 & 1607 & 90.5 \\
\hline Targets & 205 & 11.5 & 168 & 9.5 \\
\hline \multicolumn{5}{|c|}{ Self-labeled victims } \\
\hline Non-victims & 1592 & 95.8 & 1497 & 95.2 \\
\hline Victims & 70 & 4.2 & 76 & 4.8 \\
\hline
\end{tabular}

to bullying behaviors was found to be significantly associated with an increased risk of psychological distress at follow-up [odds ratio (OR) $1.68,95 \%$ confidence interval $(95 \%$ CI $) 1.07-2.62 ; \mathrm{P}=0.023]$. However, this relationship disappeared when self-labeled victimization (OR 2.47, 95\% CI 1.17-5.22; $\mathrm{P}=0.018$ ) was entered in the analyses (see table 2). Based on the Cox \& Snell R-Square and Nagelkerke R-Square values, the predictors in the second step explained between $15 \%$ and $28 \%$ of the variance in psychological distress. The regression model was supported by a significant chi-square test $\left(\chi^{2}=243.74 ; \mathrm{df}=3 ; \mathrm{P}=0.000\right)$, and by a non-significant Hosmer and Lemeshow test $\left(\chi^{2}=0.46 ; \mathrm{df}=1 ; \mathrm{P}=0.497\right)$.

Two sets of direct logistic regression analyses were performed to investigate whether psychological distress at baseline predicted exposure to bullying behavior and self-labeled victimization at follow-up (table 2). Controlling for exposure to bullying behavior at baseline (OR 7.08, 95\% CI 4.67-10.75; $\mathrm{P}=0.000$ ), results showed that symptoms of psychological distress at baseline are associated with a 2.49 times higher risk of being exposed to bullying behaviors at follow-up (OR 2.49, 95\% CI 1.64-3.80; $\mathrm{P}=0.000$ ); self-labeled victimization from bullying at baseline gave a 2.61 times higher risk of being exposed to subsequent bullying behaviors (OR 2.61, 95\% CI 1.42-4.81; $\mathrm{P}=0.000$ ). The predictors explained between $11-23 \%$ of the variance in bullying behaviors. The tests for model fit were somewhat ambiguous with both a significant chi-square test $\left(\chi^{2}=190.70 ; \mathrm{df}=3 ; \mathrm{P}=0.000\right)$ and a Hosmer and Lemeshow test $\left(\chi^{2}=7.71 ; \mathrm{df}=2 ; \mathrm{P}=0.006\right)$.

As for predicting self-labeled victimization from bullying at follow-up (table 2), findings adjusted for victimization at baseline (OR 6.92; 95\% CI 3.36-14.27; $\mathrm{P}=0.000$ ) showed that symptoms of psychological distress at baseline are associated with a 2.51 times higher risk of subsequent victimization from bullying (OR 2.51, 95\% CI 1.39-5.21; $\mathrm{P}=0.000$ ), whereas exposure to bullying behaviors at baseline is associated with a 2.95 times higher risk of victimization at follow-up (OR 2.95, 95\% CI 1.56-5.58; $\mathrm{P}=0.000$ ). In this model, the predictors explained between $6-19 \%$ of the variance in victimization from bullying. A significant chi-square $\left(\chi^{2}=93.21 ; \mathrm{df}=3 ; \mathrm{P}=0.000\right)$ and a non-significant Hosmer and Lemeshow test $\left(\chi^{2}=1.15 ; \mathrm{df}=1 ; \mathrm{P}=0.284\right)$ yielded support to the model.

\section{Discussion}

Employing a longitudinal design, this study investigated the relationship between workplace bullying and psychological distress. It was hypothesized that workplace bullying increases the risk of psychological distress, whereas 
Table 2. Longitudinal relationships between workplace bullying and psychological distress [SE=standard error; OR=0dds ratio; 95\% $\mathrm{Cl}=95 \%$ confidence interval]

\begin{tabular}{|c|c|c|c|c|c|}
\hline Baseline variables & $\mathrm{B}$ & SE & Wald chi-square & $\mathrm{OR}$ & $95 \% \mathrm{Cl}$ \\
\hline \multicolumn{6}{|l|}{ Predicting psychological distress at follow-up } \\
\hline Psychological distress & 2.7 & 0.19 & 190.29 & $14.34^{\mathrm{a}}$ & $9.82-20.93$ \\
\hline Exposure to bullying behaviors & 0.28 & 0.25 & 1.23 & 1.32 & $0.81-2.17$ \\
\hline Self-labeled victimization from bullying & 0.90 & 0.38 & 5.61 & $2.47^{\text {a }}$ & $1.17-5.22$ \\
\hline Constant & -2.7 & 0.11 & 558.82 & $0.07^{a}$ & .. \\
\hline \multicolumn{6}{|c|}{ Predicting exposure to bullying behaviors at follow-up } \\
\hline Psychological distress & 0.91 & 0.22 & 18.03 & 2.49 a & $1.64-3.80$ \\
\hline Exposure to bullying behaviors & 1.96 & 0.21 & 84.63 & $7.08^{a}$ & $4.67-10.75$ \\
\hline Self-labeled victimization from bullying & 0.96 & 0.31 & 9.56 & $2.61^{\mathrm{a}}$ & $1.42-4.81$ \\
\hline Constant & -2.98 & 0.12 & 595.05 & $0.05^{\text {a }}$ & .. \\
\hline \multicolumn{6}{|c|}{ Predicting self-labeled victimization at follow-up } \\
\hline Psychological distress & 0.92 & 0.30 & 9.31 & $2.51^{\mathrm{a}}$ & $1.39-4.52$ \\
\hline Exposure to bullying behaviors & 1.08 & 0.33 & 11.07 & $2.95^{\text {a }}$ & $1.56-5.58$ \\
\hline Self-labeled victimization from bullying & 1.94 & 0.37 & 27.49 & $6.92^{\text {a }}$ & $3.36-14 . .27$ \\
\hline Constant & -3.67 & 0.17 & 448.55 & $0.03^{a}$ & $\ldots$ \\
\hline
\end{tabular}

a $\mathrm{P}<0.001$

psychological distress also increases the risk of exposure to bullying. In addition, it was expected that victimization from bullying is a stronger predictor of psychological distress than exposure to bullying behavior.

All hypotheses received support. With regard to the effect of bullying on psychological distress, the results show that exposure to bullying behavior at baseline is significantly related to an increase in symptomatic distress two years later. Yet, the effect of workplace bullying on subsequent distress is mainly explained by the subjective feeling of being victimized by the bullying, and not by mere exposure to bullying behaviors. As for the longitudinal effects of psychological distress on workplace bullying, the results show that psychological distress predicts both exposure to bullying behaviors and victimization from bullying, thus indicating that psychological distress is an etiological factor for exposure to workplace bullying. It should be noted that the risk of developing distress after exposure to bullying is about as equally strong as the risk of being bullied at follow-up after having psychological distress at baseline. Hence, the findings from this study support a reciprocal relationship between the variables. In general, the findings of this study are congruent with the small body of existing longitudinal studies on the association between bullying and mental health (eg, $12,14)$, and also with findings on the association between interpersonal conflicts and psychological outcomes (34). For instance, in a Danish 5-year perspective longitudinal cohort study investigating long-term effects of exposure to harassment at the workplace, cross-lagged path analyses indicated that harassment and mental health mutually influenced each other (11).

Theoretical models suggest that individual vulnerability and processes of attribution are important factors for explaining the relationship between bullying and elevated health complaints $(4,35)$. Einarsen $(35)$, for instance, argues that the high levels of psychological distress found among targets of bullying may be due to a change in the target's perceptions of the work environment and life in general to one of threat, danger, insecurity, and self-questioning. Janoff-Bulman's theory (36) of cognitive trauma may be useful with regard to understanding how this process takes place. According to this theory, psychological problems following victimization are caused by the shattering of basic assumptions targets of bullying hold of themselves, other people, and the world. Thus, with regard to bullying, repeated and prolonged exposure to harassment is assumed to shatter the target's basic beliefs in justice and fairness, creating a state of anxiety and feelings of loss that subsequently have consequences on mental health. Empirical findings that support this explanation confirm that exposure to bullying is associated with worse adjustment and a weaker belief in the justness of the world, as well as symptoms of psychological trauma $(37,38)$.

In line with attribution theory (4), exposure to repeated incidences of obnoxious and degrading personal attacks that one cannot avoid or escape from, may result in feelings of helplessness. That is, by explaining their exposure to bullying with more or less stable and uncontrollable causes, targets may experience a feeling of hopelessness and resignation, as also indicated by the relatively high stability in exposure to bullying revealed in this study. This kind of pessimistic attribution style is related to lowered psychological well-being $(39,40)$. Consequently, attributions may therefore be an indirect cause of the mental health problems suffered by targets of bullying.

The finding that symptoms of psychological distress at baseline predicts bullying at follow-up is in line with the claim that any attempt to assess aggression at work must take the subjective evaluation and the physical 
and social vulnerability of the target into account (41) For instance, it might be that persons with mental health problems have a lower tolerance for exposure to bullying and, as a consequence, also have a lowered threshold for interpreting certain behaviors as bullying (4). Furthermore, those with impaired mental health may violate expectations, annoy others, and even violate social norms of polite and friendly interactions (20) and, hence, elicit aggressive behaviors in others, an explanation in line with the social interactionist perspective on aggression. It may also be the case that respondents in poorly organized work environments with high levels of frustration and interpersonal conflicts had developed mental health problems prior to the baseline survey and that these ongoing conflicts had evolved into bullying at the follow-up survey.

In accordance with previous studies (see 42 for an overview), the prevalence estimates of workplace bullying based on bullying behaviors were higher than estimates based on victimization. This finding confirms that the two measurement methods assess different aspects of the bullying phenomenon (28) and that not everybody exposed to bullying behaviors self-labels as a victim. Still, the prevalence estimates of bullying found at the two survey time-points in this study are significantly lower than worldwide estimates using the same measurement methods, but in line with other studies on prevalence of workplace bullying from Scandinavia (see 42 for an overview of figures). Hence, in addition to showing that the prevalence of bullying has been more or less stable over a 2-year period in Norway, the findings confirm the relatively low occurrence of bullying in Northern Europe.

In the current study, we investigated psychological distress during the last week before the survey. The findings showed that about $13 \%$ of the sample reported psychological distress above threshold values. In comparison, a recent report on the occurrence of psychological disorders in Norway shows that about one third of Norwegian adults have some sort of psychological disorder during a given year (43). Hence, as our study has investigated the prevalence of psychological distress within a sample of vocational active persons using a relatively short time span (ie, one week), it is reasonable that our figures are somewhat lower than numbers reported in a study that also includes citizens outside working life and that uses a longer survey period.

\section{Methodological strengths and limitations}

Compared to most of the existing research on the relationship between workplace bullying and health, a strength of this study is that it investigates bullying and health by utilizing a longitudinal design in a large nationwide and representative sample. Hence, the findings may be considered more reliable than findings from non-random cross-sectional sampled studies and should therefore be generalizable to the total working population in Norway (cf, 44). However, as the sample was somewhat skewed with regard to age and gender, one may want to take these two variables into consideration when comparing the findings with other studies. Because the analyses of the associations between bullying and mental health were longitudinal and were controlled for mental health at baseline, we can be quite sure of the direction of the association from exposure to response (11). A final strength that ought to be mentioned is that the response rates of this study are above the average response rates for organizational survey research (22), with the response rate at follow-up being as high as $70 \%$.

As for limitations of the study, it should be noted that our design was based on only two measurement points with a 2-year time lag. Longitudinal studies using several measurements points over an extended period of time, for instance diary studies, might add to our knowledge of the short-term dynamics as well as the long-term changes in bullying and mental health. Finally, as all data were collected using self-report questionnaires, there is the possibility of common method variance and response set tendencies (45). Yet, the time-lag of two years contributes to the reduction of this tendency somewhat (46). Related to this, relying on self-report methodology may be problematic with regard to assessing workplace bullying and psychological distress due to feelings of shame and guilt among respondents. Although anonymity is ensured, there is a possibility that individuals will underreport bullying and distress. Such underreporting may attenuate correlations between the variables because error is introduced in the observed relationship (47) and, in the worst case, lead to a type-II error.

\section{Concluding remarks}

Having examined the longitudinal associations between workplace bullying and psychological distress, we conclude that workplace bullying is a significant predictor for subsequent mental health problems among employees, with mental health problems at baseline also being a predictor for later exposure to bullying. The impact of bullying is especially severe when one perceives oneself as a victim. These findings have implications for theory, research, and practice. With regard to theory and research, the mutual relationship between bullying and mental health supports the idea of a vicious circle where bullying and psychological distress reinforce their own negative effects through feedback loops (12).

With regard to practice, our results indicate that organizations must give high priority to the prevention 
and management of bullying. As high levels of psychological distress have a major negative impact on both job satisfaction and quality of life, early identification and prevention of bullying may be a key factor in attempts to minimize the adverse effects of workplace bullying on mental health. Organizations may implement a range of measures to combat bullying. Such measures include anti-bullying policies, training and information, appropriate job designs, active monitoring, and early intervention (48).

As a first preventive step, organizations should implement an anti-bullying policy. Such a policy contains an explicit managerial commitment to a bullyingfree environment, examples of bullying behaviors, complaints procedures, and possible consequences for perpetrators (48). As psychological distress is associated with an increased risk of exposure to workplace bullying, job designs that take individual characteristics into consideration may also be important as a preventive measure against bullying. As for how episodes of bullying should be handled, active monitoring and early interventions are necessary to reduce possible negative consequences. The presence of well-planned procedures for investigations of complaints and their proper implementation provides the organization with an opportunity to make correct decisions, re-establish fairness, and bring the matter to a conclusion (49). In addition, proper interventions provide security for the individual and send a strong signal to employees that these issues are taken seriously and not tolerated by the organization (50). However, if bullying is allowed to escalate, the findings of this study show that the individual consequences can be severe. At the organizational level, the costs of bullying for an enterprise can be considerable, as relatively small effects on the individual level may have substantial aggregated or cumulative effects within an organization (51).

\section{Acknowledgements}

This study was based on data from a collaborative project between the University of Bergen and Statistics Norway (Statistisk Sentralbyrå); the latter institution drew the sample and collected the data. Thanks to Bengt Oscar Lagerstrøm and Maria Høstmark of Statistics Norway and to Anders Skogstad at the Faculty of Psychology at the University of Bergen for their contribution to the data collection.

The project was made possible by joint grants from two Norwegian employers' associations (Næringslivets Hovedorganisasjon and Kommunenes Sentralforbund) and the Norwegian government (Rikstrygdeverket).

\section{References}

1. Einarsen S, Hoel H, Zapf D, Cooper CL. The concept of bullying and harassment at work: The European tradition. In: Einarsen S, Hoel H, Zapf D, Cooper CL, editors. Bullying and harassment in the workplace Developments in theory, research, and practice. 2nd ed. Boca Raton: CRC Press; 2011. p3-40.

2. Einarsen S. The nature and causes of bullying at work. Int $\mathrm{J}$ Manpower. 1999;20:16-27. doi:10.1108/01437729910268588.

3. Aquino K, Thau S. Workplace victimization: Aggression from the target's perspective. Annu Rev Psychol. 2009;60:717-41. doi:10.1146/annurev.psych.60.110707.163703.

4. Bowling NA, Beehr TA. Workplace harassment from the victim's perspective: A theoretical model and meta analysis. J Appl Psychol. 2006;91:998-1012. doi:10.1037/00219010.91.5.998

5. Niedhammer I, Chastang J-F, David S. Importance of psychosocial work factors on general health outcomes in the national French SUMER survey. Occup Med. 2008;58:15-24. doi:10.1093/occmed/kqm115.

6. Quine L. Workplace bullying, psychological distress, and job satisfaction in junior doctors. Camb Q Healthc Ethics. 2003;12:91-101. doi:10.1017/S0963180103121111.

7. Mikkelsen EG, Einarsen S. Bullying in Danish worklife: Prevalence and health correlates. European Journal of Work and Organizational Psychology. 2001;10:393-414. doi:10.1080/13594320143000816.

8. Vie TL, Glaso L, Einarsen S. Health outcomes and selflabeling as a victim of workplace bullying. J Psychosom Res . 2011;70:37-43. doi:10.1016/j.jpsychores.2010.06.007.

9. Hansen ÅM, Høgh A, Persson A, Karlson B, Garde AH, Ørbæk P. Bullying at work, health outcomes, and physiological stress response. J Psychosom Res. 2006;60:63-72. doi:10.1016/j. jpsychores.2005.06.078.

10. Zapf D, Knorz C, Kulla M. On the relationship between mobbing factors, and job content, social work environment, and health outcomes. Eur J Work Organ Psy. 1996;5:215-37. doi:10.1080/13594329608414856.

11. Høgh A, Henriksson ME, Burr H. A 5-year follow-up study of aggression at work and psychological health. Int J Behav Med. 2005;12(4):256-65. doi:10.1207/s15327558ijbm1204_6.

12. Kivimäki M, Virtanen M, Vartia M, Elovainio M, Vathera J, Keltikangas-Järvinen L. Workplace bullying and the risk of cardiovascular disease and depression. Occup Environ Med. 2003;60:779-83. doi:10.1136/oem.60.10.779.

13. Kivimäki M, Elovainio M, Vathera J. Workplace bullying and sickness absence in hospital staff. Occup Environ Med. 2000;57:656-60. doi:10.1136/oem.57.10.656.

14. Brousse G, Fontana L, Ouchchane L, Boisson C, Gerbaud L, Bourguet D, et al. Psychopathological features of a patient population of targets of workplace bullying. Occup Med. 2008; 58: 122-8. doi:10.1093/occmed/kqm148.

15. Kivimäki M, Leino-Arjas $\mathrm{P}$, Virtanen $\mathrm{M}$, Elovainio $\mathrm{M}$, Keltikangas-Järvinen L, Puttonen S, et al. Work stress and 
incidence of newly diagnosed fibromyalgia. Prospective cohort study. J Psychosom Res. 2004;57:417-22. doi:10.1016/ S0022-3999(03)00620-2

16. Jex SM. Organizational psychology. A scientist-practitioner approach. New York: John Wiley \& Sons, Inc; 2002. 17. Beehr TA. An organizational psychology meta-model of occupational stress. In: Cooper CL, editor. Theories of organizational stress. Oxford: Oxford University Press; 1998. p6-27.

18. Ursin H, Eriksen HR. The cognitive activation theory of stress. Psychoneuroendocrino. 2004 Jun;29(5):567-92. doi:10.1016/ S0306-4530(03)00091-X.

19. Coyne I, Seigne E, Randall P. Predicting workplace victim status from personality. Eur J Work Organ Psy. 2000;9(3):33549. doi:10.1080/135943200417957.

20. Felson RB. "Kick 'em when they're down": Explanations of the relationships between stress and interpersonal aggression and violence. Sociol Q. 1992;33(1):1-16. doi:10.1111/j.1533-8525.1992.tb00360.x.

21. de Lange AH, Taris TW, Kompier MAJ, Houtman ILD, Bongers PM. Different mechanisms to explain the reversed effects of mental health on work characteristics. Scand J Work Environ Health. 2005;31(1):3-14.

22. Baruch Y, Holtom BC. Survey response rate levels and trends in organizational research. Hum Relat. 2008;61(8):1139-60. doi: $10.1177 / 0018726708094863$.

23. Høstmark M, Lagerstrøm BO. Undersøkelse om arbeidsmiljø: Destruktiv atferd i arbeidslivet. Dokumentasjonsrapport (A study of work environments: Destructive behaviours in working life. Documentation report). Oslo: Statistisk Sentralbyrå/Statistic Norway 2006. Report No: 44.

24. Berthelsen M, Skogstad A, Hauge LJ, Nielsen MB, Einarsen S. Mobbing og utstøting i arbeidslivet: Resultater fra en landsrepresentativ og longitudinell undersøkelse [Bullying and exclusion from working life. Findings from a representative and longitudinal survey]. Bergen: Universitetet i Bergen 2008.

25. Einarsen S, Hoel H, Notelaers G. Measuring bullying and harassment at work: Validity, factor structure, and psychometric properties of the Negative Acts Questionnaire - Revised. Work Stress. 2009;23(1):24-44. doi:10.1080/02678370902815673.

26. Notelaers G, Einarsen S. Distinguishing between targets and non targets of bullying: Applying a roc-analysis to the Negative Acts Questionnaire. Paper presented at the 14th European Congress Work and Organizational Psychology; 12 May; Santiago de Compostela 2009.

27. Leymann H. The content and development of mobbing at work. Eur J Work Organ Psy. 1996;5:165-84. doi:10.1080/13594329608414853.

28. Nielsen MB, Notelaers G, Einarsen S. Measuring exposure to workplace bullying. In: Einarsen S, Hoel H, Zapf D, Cooper $\mathrm{CL}$, editors. Bullying and Emotional Abuse in the Workplace Developments in Theory, Research and Practice. Boca Raton: CRC Press; 2011.

29. Einarsen S, Skogstad A. Bullying at work: Epidemiological findings in public and private organizations. Eur J Work Organ
Psy. 1996;5:185-201. doi:10.1080/13594329608414854.

30. Derogatis LR, Lipman RS, Rickels K, Uhlenhuth EH, Covi L. The Hopkins Symptom Checklist (HSCL): A self report symptom inventory. Behav Sci. 1974;19(1):1-15. doi:10.1002/bs.3830190102.

31. Nettelbladt P, Hansson L, Stefansson C-G, Borgquist L, Nordström G. Test characteristics of the Hopkins Symptom Check List-25 (HSCL-25) in Sweden, using the Present State Examination (PSE-9) as a caseness criterion. Soc Psychiatry Psychiatr Epidemiol. 1993;28:130-3. doi:10.1007/ BF00801743.

32. Hesbacher PT, Rickels K, Morris RJ, Newman H, Rosenfeld H. Psychiatric-Illness in Family-Practice. J Clin Psychiatry. 1980;41(1):6-10

33. Strand BH, Dalgard OS, Tambs K, Rognerud M. Measuring the mental health status of the Norwegian population: A comparison of the instruments SCL-25, SCL-10. SCL-5 and MHI-5 (SF-36). Nord J Psychiatry. 2003;57:113-8. doi:10.1080/08039480310000932.

34. Romanov K, Appelberg K, Honkasalo M-L, Koskenvou M. Recent interpersonal conflict at work and psychiatric morbidity: A prospective study of 15,530 employees aged 24-64. J Psychosom Res. 1996;40(20):169-76. doi:10.1016/0022-3999(95)00577-3.

35. Einarsen $\mathrm{S}$. The nature, causes and consequences of bullying at work: The Norwegian experience. Pistes. 2005;7(3):1-14.

36. Janoff-Bulman R. Shattered assumptions. Towards a new psychology of trauma. New York: The Free Press; 1992.

37. Adoric VC, Kvartuc T. Effects of mobbing on justice beliefs and adjustment. Eur Psychol. 2007;12(4):261-71. doi:10.1027/1016-9040.12.4.261.

38. Mikkelsen EG, Einarsen S. Basic assumptions and symptoms of post-traumatic stress among victims of bullying at work. Eur J Work Organ Psy. 2002;11:87-111. doi:10.1080/13594320143000861.

39. Gray MJ, Pumphrey JE, Lombardo TW. The relationship between dispositional pessimistic attributional style versus trauma-spesific attribution and PTSD symptoms. J Anxiety Disord. 2003;17:289-303. doi:10.1016/S08876185(02)00205-0.

40. Peterson C, Seligman MEP. Causal explanations as a risk factor for depression: Theory and evidence. Psychol Rev. 1984;91:347-74. doi:10.1037/0033-295X.91.3.347.

41. Painter K. Violence and vulnerability in the workplace: Psychosocial and legal implications. In: Davidson MJ, Earnshaw J, editors. Vulnerable worker: Psychosocial and legal issues. New York: John Wiley \& Sons; 1991. p160-78.

42. Nielsen MB, Matthiesen SB, Einarsen S. The impact of methodological moderators on prevalence rates of workplace bullying. A meta-analysis. J Occup Organ Psychol. 2010;83(4):955-79. doi:10.1348/096317909X481256.

43. Mykletun A, Knudsen AK, Mathiesen KS. Psykiske lidelser i Norge: Et folkehelseperspektiv [Psychological disorders in Norway: A public health perspective]. Oslo: Nasjonalt folkehelseinstitutt 2009 . 
44. Nielsen MB, Einarsen S. Sampling in research on interpersonal aggression. Aggress Behav. 2008;34(3):265-72. doi:10.1002/ ab.20229.

45. Spector PE. Method variance in organizational research - Truth or urban legend? Org Res Methods. 2006 Apr;9(2):221-32. doi:10.1177/1094428105284955.

46. Podsakoff PM, MacKenzie SB, Lee JY, Podsakoff NP. Common method biases in behavioral research: A critical review of the literature and recommended remedies. J Appl Psychol. 2003 Oct;88(5):879-903. doi:10.1037/00219010.88.5.879.

47. Spector PE, Fox S. The stressor-emotion model of counterproductive work behavior. In: Fox S, Spector PE, editors. Counterproductive behavior Investigations of actors and targets. Washington, DC: American Psychological Association; 2005. doi:10.1037/10893-007.

48. Salin D. The prevention of workplace bullying as a question of human resource management: Measures adopted and underlying organizational factors. Scand J Manag. 2008;24(3):221-31. doi:10.1016/j.scaman.2s008.04.004.
49. Hoel H, Einarsen S. Investigating complaints of bullying and harassment. In: Einarsen S, Hoel H, Zapf D, Cooper $\mathrm{CL}$, editors. Bullying and harassment in the workplace Developments in theory, research, and practice. Boca Raton: CRC Press; 2011. p341-58.

50. Stockdale MS, Sagrestano LM. Strategies and resources for institutions and targets of sexual harassment in employment and education. In: Paludi M, Denmark FL, editors. Victims of sexual assault and abuse: Resources and responses for individuals and families. San Francisco: Praeger; 2010. p211-39.

51. Daniels K, Harris C. Work, psychological well-being and performance. Occup Med. 2000;50(5):304-9.

Received for publication: 13 January 2011 